\title{
Psychotherapy training in a community mental health feam
}

\author{
Elaine C. Ogg
}

\begin{abstract}
A one year training post at senior registrar level in psychotherapy in a developing community mental health feam is described, not only for tis relevance to troining of all levels but also as an example of how general psychiatry and psychotherapy can work together to promote good psychiatric practice in a community team.
\end{abstract}

I spent one year as senior registrar in psychotherapy at the Shawpark Centre, Glasgow, a developing community mental health team. Training in this setting provides the opportunity for the full range of experience at all training levels and includes a valuable opportunity to gain the skills required for community psychiatry which differs from hospital based psychiatry. This type of placement also has shown the benefit of general psychiatry and psychotherapy colleagues working together, reducing the potential for antagonism that has existed in the past. It shows a possible future place for psychotherapy in the NHS, integrated more with general psychiatry.

\section{Description of the team}

Maryhill is an inner city ward of Glasgow with a population of 48,000 and relatively high levels of psychiatric morbidity and social deprivation (Jarman scores +14 to +48 ). In January 1993, as part of Greater Glasgow Health Board's move towards community care for the mentally ill, a community mental health team was established. The Team, based in a purpose-built central location, attached to a health centre, initially consisted of one team manager, 18 nursing staff, one consultant psychiatrist, one halftime consultant psychotherapist (my trainer), myself and three clerical staff. After six months time another full-time consultant psychiatrist and a staff grade psychiatrist were appointed as well as a clinical psychologist and an occupational therapist. The centre catered for clients ( 16 to 65 years old) with a broad range of psychiatric problems, but severe mental illness was prioritised. Day care at the centre included group work, individual work and a drop-in centre while home treatment was also offered and included a 24-hour crisis service.

\section{The psychotherapy service}

Patients were assessed by the consultant or myself, or both, often in conjunction with nursing staff. Referrals were accepted from general practitioners and from within the team, including consultation/liaison work with more disturbed patients. Brief or longterm psychodynamic psychotherapy was offered, both individually and in groups. The psychotherapist would often work jointly or in a supervisory capacity with the nursing staff, especially with more borderline patients giving the opportunity for staff training and assessment.

\section{The role of senior registrar}

\section{Clinical work}

The main clinical psychotherapy work is described above but I was also involved in some general psychiatric crisis work with acutely disturbed patients. Where appropriate, cognitive therapy was used supervised by the clinical psychologist.

\section{Staff training and supervision}

The need was recognised for training of staff in the assessment and continuing care of patients in the community since team members worked in a more autonomous way than when hospital based. Through formal joint assessments/supervision as well as informal discussion we were able to facilitate this change in practice. This was particularly useful for the 24-hour crisis service. 
Team development and support

Psychotherapy training was helpful in understanding the dynamics of institutional change. Being present from the outset and watching the team develop was a useful preparation for work as a consultant in the community.

Outside consultancy was provided in the form of team meetings facilitated by the Scottish Institute of Human Relations and a residential course in team building offered by the Centre for Mental Health Services Development Group. These were both useful for daily work and as learning experiences.

It was helpful to read of difficulties encountered in organisations elsewhere (Hinshelwood, 1987) but it was invaluable to have first-hand experience of working through issues such as rivalries, role confusion changing hierarchies and the loss of the containing function of the hospital while maintaining training needs and delivering a service.

\section{The benefits of this type of training}

(a) Hospital-based psychiatry and community psychiatry utilise different skills, thus all disciplines require training to deal with this new mode of working and the loss of the 'containing' function of the hospital.

(b) The role of the consultant psychiatrist within the team is particularly important and requires specialist training to deal with difficult issues such as managing overall responsibility and professional rivalries.

(c) The psychotherapist can be a useful member of the team both in dealing with a wide range of patients and supporting staff. The use of psychodynamic principles can facilitate the development of the team. I believe more use should be made of these skills in the future development of community mental health teams both from within and without.

(d) As a training post in psychotherapy at a higher professional level, this type of placement fulfils most of a trainee's needs. It would also be an efficient way of meeting the College guidelines for psychotherapy training at general professional level (Grant et al, 1993) as it includes different models of psychotherapy, experience of team development, organisational functioning and management of occupational stress.

\section{The drawbacks of this type of training}

The creation and development of a community mental health team is a difficult process for all concerned. It could be said that all staff are training in a new field and therefore the needs of trainees could be overlooked given the needs of the team as a whole. As Kraemer (1994) described, they can be seen as troublesome infants in the team 'family'. The problem is confounded for senior trainees whose experience can be used to supervise others rather than being supervised themselves. In addition there is pressure from managers for the team to succeed and provide a service which can lead to training being of secondary importance. It is essential that staffing levels are adequate and trainers are given time for supervision.

\section{Comment}

Since community psychiatry is the future plan for mental health services, this type of 'hands on' training is essential for all training levels both as preparation for a consultant post and to meet the needs of psychotherapy training in general psychiatry. My experience is that the psychotherapist can play an important role as co-therapist of all categorles of patients and in the support and development of the team.

\section{Acknowledgements}

I would like to thank Dr S. Grant and the staff of the Shawpark Centre, Glasgow for their support and suggestions.

\section{References}

Grant, S., Holmes, J. \& Watson, J. (1993) Guidelines for psychotherapy training as part of general professional training. Psychiatric Bulletin, 17, 695-698.

HinsHelwOOD, R. D. (1987) What Happens in Groups: psychoanalysis, the individual and the community. Karnac Books.

KRAEMER. S. (1994) On worktng together in a changing world: dilemmas for the trainer. ACPP Review and Newsletter. 16, no 3.

Elaine C. Ogg, Senior Registrar in Psychotherapy, Glasgow Community and Mental Health Unit Trust, The Shawpark Centre, 41 Shawpark Street, Glasgow G20 9DR 